If the bearing of a vessel echo is steady to starboard or is closing, a turn by the shortest direction shall be made towards the other side of the sight line; if the echo bears steady to port or is opening, the heading shall be kept on the same side of the sight line.

3. Conclusion. This Pair Rule is simpler than the manœuvring rules I have proposed previously ${ }^{1}$, but all of them are simple because they only work out the operational aspect of the collision problem; the organic aspect is solved by the Sector Rule1, which involves the best guarantee of a safe passing.

R E F E R E N C E

1 Garcia-Frias, J. (1965). The sector rule and the collision problem. This Journal, 18 , 141.

\title{
The Vinland Map
}

\section{R. A. Skelton}

THE January issue of the Journal (pp. I 24-5) contained a summary of Professor E. G. R. Taylor's views on the Vinland Map. To the courtesy of the Editor I owe the opportunity both to read this note in proof and to comment on it in the present issue. I have not seen Professor Taylor's complete study nor her drawings. She expressed some of her misgivings to me in correspondence after (in 1 962) seeing a photocopy of the map and reading in typescript my study of the map, which is included in the recently published monograph.

Professor Taylor's judgment was formed from examination of the map, without knowledge of the two textual documents with which it is associated or of the common physical characteristics which link it to them. That these other documents-the Tartar Relation and a fragment of the Speculum historiale of Vincent of Beauvais--are authentic, and that they were copied (i.e. written) about 1440 , probably in the Upper Rhineland, are conclusions on which no doubt has yet been expressed; nor does it seem likely that any could be seriously sustained. It must however be recognized that, strong as are the arguments (from palaeography, bibliotics and content) that connect the map with these documents, the view that it is a modern counterfeit cannot, in the absence of information on its history, be absolutely disproved. One can even visualize possible methods by which a hypothetical forger might have gone to work to produce such a map.

We must understand clearly what kind of evidence is required to settle the issue of authenticity positively one way or the other. Obviously the history of the map and of the associated textual documents would do so, if and when it comes to light. So too would chemical analysis of the materials (vellum, ink), could this be undertaken without risk. Yale University Library bears the responsibility for preservation of the documents, and (in the words of the foreword to the monograph) 'all [physical] tests that would not involve damage or destruction of the manuscript have been applied'. The fact that these tests, together with analysis of the form and content of the map in the historical 
context, have created in the minds of those who have studied the original 'a presumption of authenticity so strong as to be difficult, if not impossible, to challenge' does not of course amount to legal proof. No artefact whose history is unknown is immune from the hypothesis of perfect or near-perfect forgery. This applies both to works whose authenticity is disputed and to those whose authenticity has never been doubted.

The only other method of proving this hypothesis (besides those mentioned above) is the detection of flaws in the work of the counterfeiter, i.e. historical anomalies, errors or anachronisms which are inconsistent with the date at which the artefact-in this case the Vinland Map-appears to have been made. This is the method applied by Professor Taylor to the cartographic evidence; my comments on her criticisms in detail are given below. Minute and expert scrutiny of the names and legends in the map, letter by letter and word by word, has so far revealed no palaeographical anomalies or errors; the hand, in all its characteristics, matches that of the textual documents. The content of the legends also stands up to historical criticism.

The map's novelty of content is not enough to discredit it. Nevertheless, if it can be shown to contain elements, or to incorporate information, of a later date than the fifteenth century, it must be condemned as a forgery, albeit one of a perfection and accomplishment not conceivable before the twentieth century. If, on the other hand, searching attempts by those most versed in early maps fail to demonstrate any such cartographic anomalies and errors, judgment on the map's authenticity need not await discovery of its history. We are then justified in considering it as a genuine product of the mid-fifteenth century, and must make the necessary adjustments in our ideas on cartographic history.

It is accordingly imperative to determine whether Professor Taylor's criticisms of the map are valid. As shown below, they do not seem to me to have any substance. Since they are mainly founded on errors of method and (surprisingly in so mature a scholar) on misapprehension of the character and construction of medieval world maps generally, I do not suppose that her 'detailed proofs' (which I have not had the opportunity of seeing) would be found more convincing than the summary of them printed in the Journal.

It is with a sense of personal regret that I make these comments. If in this case I am bound to consider her judgment at fault, it does not diminish my admiration for Professor Taylor's very fruitful contributions to the history of medieval cartography nor the debt which, in common' with other students, I owe to her past work in this field, which has been distinguished by keen perception, power of association, and range of reference.

In the following comments on Professor Taylor's five 'principal points', I have added parenthetical references to the published monograph, The Vinland Map and the Tartar Relation, for the benefit of those who may wish to pursue any of the arguments further.

I. Although the Vinland Map is not bounded by a drawn ellipse, the outlines and proportions of the Old World as represented in it form a rough ellipsoid ( $V M$, p. I 1 4$)$. This is not the only medieval map of ellipsoid or ovoid shape. The plate cited by Professor Taylor in the manual on map projections by Deetz and Adams is that of Aitoff's equal-area projection, Plate V. The conformity between its bounding line and the outer edges of the inked design in the Vinland Map seems far too limited to justify the inference that the cartographer knew and used the formula for constructing an ellipse; and Professor Taylor apparently 
does not press this argument. The shape of the design (as of some other medieval world maps) was plainly produced by adaptation of an original circular outline, by vertical compression, in order to fit the rectangular space provided by a sheet of vellum or paper or by the opening of a codex ( $V M, \mathrm{pp}$. 1 14-15, 1 1 8-19). The proportion between the axes, approximately $2: 1$, is the same as in the so-called 'Genoese' world map, of lenticular form, dated 1457; it has never been suggested that the draughtsman of the 'Genoese' map was aware of the eccentricity of a closed elliptical figure.

2. The position of the Shetlands and Faeroes in the Vinland Map, in relation to the British Isles and Norway, corresponds to the delineation in Andrea Bianco's world map of 1436 (which reflects a similar model for the tripartite world as a whole), but is quite different from that in Mercator's world map of I 569 . In adding Iceland to the design, the cartographer certainly creates a pattern of the Shetlands-Faeroes-Iceland which has a general-hardly a 'precise'visual similarity to that in Mercator's map. Professor Taylor prudently concedes that 'this might be coincidence'. In comparing selected details in small-scale maps of generalized and simplified design, 'measurements' may be extremely misleading if used to deduce affinity, influence or copying. By this method it could be shown that other medieval maps whose authenticity is not in doubt were derived from much later maps of the Renaissance.

3. In criticising the representations of Crete and the Aegean in the Vinland Map, Professor Taylor again appears to overlook the consequences of generalization. A like criticism could be made of Bianco's world map if it were compared with the larger-scale charts (of which, in this area, it seems to be a reduction) in his atlas of 1436 . That the compiler of the Vinland Map (whether he worked in the fifteenth or in the twentieth century) must have had access to a model of the late fourteenth or early fifteenth century, very similar to Bianco's, cannot be disputed. There are no grounds for supposing, nor is it suggested in the monograph, that he was 'familiar with Italian maps'; rather the contrary, in view of his evident preference for a single source. The Sea of Marmora is not 'omitted', but is clearly drawn in a form recognizably generalized from that seen in Bianco's world map. The Bosphorus, and consequently the 'site for Constantinople', appear exactly as in Bianco. Professor Taylor's comments here seem somewhat captious.

4. The West African coastline, as drawn in the Vinland Map, shows no more and no less than Bianco's map of 1436 and reflects the same horizon of knowledge. If this be taken as a test of authenticity, Bianco's map must also be condemned, or at any rate assigned to a date much later than 1436 ; and even the Catalan Atlas of I 375 comes under suspicion. The uncontrolled correlation of the progress of discovery, as imperfectly revealed by surviving documents, with cartographic representations is notoriously hazardous.

5. Three points are made here. (a) The delineation of Greenland as an island is certainly 'the most remarkable feature of the Vinland Map', and (Professor Taylor might have added) the most perplexing. While her comment on the improbability of exploration by the Greenlanders suggests defective knowledge of their economy, it remains very difficult to accept that they could have circumnavigated Greenland. For the completion of the outline in the map by the drawing of a north coast, this is only one of the alternative hypotheses set out in the monograph ( $V M$, pp. 195-6), with the rider that 'for none of (them) can a high degree of probability be claimed'. (b) The 'map of southern Greenland', of 
$135 \mathrm{I}$, cited by Professor Taylor is that in the Laurentian or Medici atlas (reproduced in $V M, \mathrm{pl}$. VIII). Although the place names in this map indicate that the cartographer intended the feature to represent the south-west peninsula of Norway, its outline was adopted, in and after 1424, to illustrate Claudius Clavus' descriptions of Greenland. On the fundamental difference between this rendering and that in the Vinland Map, I am in agreement with Professor Taylor ( $V M$, pp. 189-9o). (c) Her suggestion that a fifteenth-century world map, in which the several parts were compiled from different sources, must-or even could-have been drawn on a uniform scale throughout, will surprise other students of medieval cartography. Portolan charts, which generally (not 'always') bore a scale of leagues, were designed for pilotage and drawn on an appropriate scale, and they usually depicted relatively short tracts of coastline. Of all the world maps (other than those of Ptolemaic type) drawn before i 500 , whether by chartmakers (such as Petrus Vesconte and Bianco) or by men of the study (such as Walsperger, Leardo and Fra Mauro), none has a latitude-scale; and in the very few cases where a league-scale occurs, this applies only to the Mediterranean area for which portolan charts supplied the model. A good (if later) example of variation of scale on the two sides of the Atlantic is provided by the world map of Juan de La Cosa dated 1500 , which (as G. R. Crone has shown) depicts America on a much greater scale than the Old World, and from materials of different origin and date. It is impossible to agree with Professor Taylor that such apparent differences of scale within the Vinland Map are inconsistent with the date ascribed to it.

M. W. Richey comments:

Mr. Skelton appears rather to have missed the point about the close fit which the outline of the Vinland Map makes with the Aitoff projection illustrated in the work of Deetz and Adams, perhaps through shortcomings in my own description of Professor Taylor's views. The outline of the map (if the north point is shifted about two points to the eastward, in accordance with the westerly magnetic variation as discussed in various numbers of Imago Mundi) fits the outline of the illustration in Deetz and Adams to nearly one tenth of an inch. In addition, of course, as G. R. Crone points out (Geographical Journal, March 1966), no other contemporary cartographers appear to have used the ellipse. 